University of Wollongong

Research Online

Faculty of Engineering and Information

Faculty of Engineering and Information

Sciences - Papers: Part B

Sciences

2016

Discussion: Assessment of smear parameters for use in wick drain design

Richard B. Kelly

University of Wollongong

A Litwinowicz

GHD

Follow this and additional works at: https://ro.uow.edu.au/eispapers1

Part of the Engineering Commons, and the Science and Technology Studies Commons

Research Online is the open access institutional repository for the University of Wollongong. For further information contact the UOW Library: research-pubs@uow.edu.au 


\title{
Discussion: Assessment of smear parameters for use in wick drain design
}

\author{
Abstract \\ As the paper's findings (Kelly, 2014) are premised on 100\% degree of consolidation being achieved, which \\ in itself has inherent uncertainties, the consolidation aspect is worthy of closer examination. In this \\ discussion, Consolidation (capital $\mathrm{C}$ ) refers specifically to primary consolidation being the traditional \\ time-dependent expulsion of water volume under pressure with progress assessed by change in pore \\ pressure. Moreover, the Consolidation phase is most relevant to wick drain effectiveness. \\ Disciplines \\ Engineering | Science and Technology Studies \\ Publication Details \\ Kelly, R. B. \& Litwinowicz, A. (2016). Discussion: Assessment of smear parameters for use in wick drain \\ design. Proceedings of the Institution of Civil Engineers: Ground Improvement, 169 (2), 150-153.
}




\section{Discussion: Assessment of smear parameters for use in wick drain design}

\section{R. Kelly BE, PhD, FIEAust}

Chief Technical Principal, SMEC Australia Honorary Professorial Fellow, University of Wollongong; Visiting Industry Fellow, Centre of Excellence for Geotechnical Science and Engineering, University of Newcastle, Australia
A. Litwinowicz FIE Aust

GHD Pty Ltd, Brisbane, Australia

\section{Contribution by A. Litwinowicz}

As the paper's findings (Kelly, 2014) are premised on 100\% degree of consolidation being achieved, which in itself has inherent uncertainties, the consolidation aspect is worthy of closer examination. In this discussion, Consolidation (capital C) refers specifically to primary consolidation being the traditional time-dependent expulsion of water volume under pressure with progress assessed by change in pore pressure. Moreover, the Consolidation phase is most relevant to wick drain effectiveness.

Figure 8 reproduces the 'Settlement data' points for Pimlico Clay depicted in the degree of consolidation Figures 2 and 4 of the paper. Figure 8 also presents plots of the degree of consolidation by taking the total settlement-time dataset from Figure 1 and calculating the degree of consolidation using the $100 \%$ settlement values from Table 1 as reference.

The match of the derived datasets confirms that total settlement is used to calculate the degree of consolidation, which contrasts with the traditional definition for degree of Consolidation. As total settlement includes recompression to yield and other forms of non-Consolidation settlement, this approach inevitably overestimates the Consolidation progress; however, it is not possible to determine the extent of this overestimation with the presented data.

To explore this further, Figure 9 reproduces the settlement-time data from Figure 1 in conventional log-time space together with data from the Cumbalum trial embankment (Kelly, 2008) located in the same geographical area and built on the same foundation geological setting - that is, Pimlico Clay. The trial plot closely mimics the data from the paper's site with the same $1.35 \mathrm{~m}$ wick drain spacing, to the extent that it appears to be from the same location, or perhaps in close proximity.

Putting aside the last data point for the unidentified site with wicks at $1.35 \mathrm{~m}$ spacing, which appears inconsistent, the following observations are apparent.

- A large portion of the total settlement occurs during periods of fill placement and from the settlement trend it appears that filling may have continued past the completion times reported.

- Soon after completion of fill placement, the settlement establishes an approximately linear trend in log-time without any sign of abatement.

- The linear settlement rates are depicted in Figure 9 as per-cent strain/log cycle of time based on the depth of soft soil in Table 1, and are significantly higher than could be attributed to creep, noting that an average strain rate for the total thickness underestimates localised strain rates in consolidating zones due to Consolidation nearing completion around drainage boundaries.

- For the 1.0 and $1.5 \mathrm{~m}$ wick spacing, the linear log-time trend continues past the $100 \%$ settlement values given in Table 1 of the paper; this is also likely for the $1.35 \mathrm{~m}$ wick spacing where the last data point appears errant (embankment unloading or instrument damage occurred?), supported by the Cumbalum trial data, which show a similar ongoing trend for an additional 2 years or so until further filling.

Piezometers are not referenced in the paper but were installed at the original Cumbalum trial embankment (Allman, 2004; Kelly, 2008). Kelly (2008) discusses one piezometer, PC2/5.8 at $5.8 \mathrm{~m}$ depth, in a single vertical string of piezometers at the centre of the trial. At $\sim 4.5$ years (around the time of the last reading at the unnamed site with wicks at $1.35 \mathrm{~m}$ ), PC2/5.8 had $20 \mathrm{kPa}$ excess pore pressure - that is, $\sim 25 \%$ Consolidation remaining based on the maximum pore pressure recorded. This is similar to Allman's assessment of PC2/5.8, indicating $\sim 23 \%$ Consolidation remaining at 3.5 years, and noting that both of these excess pore pressures were corrected by the author to account for instrument settlement. It appears that full pore pressure dissipation and hence $100 \%$ Consolidation was not reached at the location of this piezometer. However, in the soil profile Consolidation continued and, given the data presented, it was not possible to determine the actual overall Consolidation progress or the overall representativeness of $\mathrm{PC} 2 / 5.8$ with respect to the likely complex foundation drainage characteristics.

It is also of some relevance to note that the non-singular solution to wick drain disturbance can be sensitive to small 


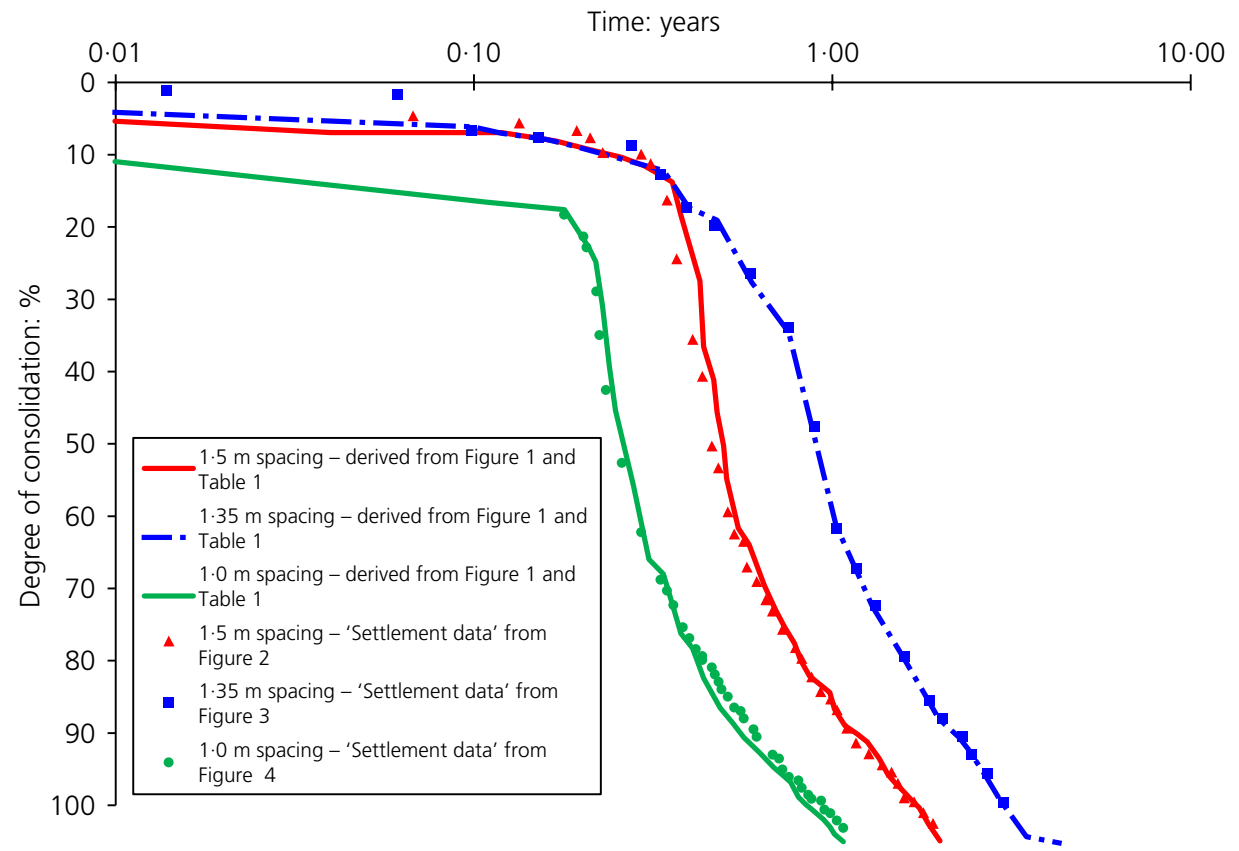

Figure 8. Degree of consolidation plotted against time

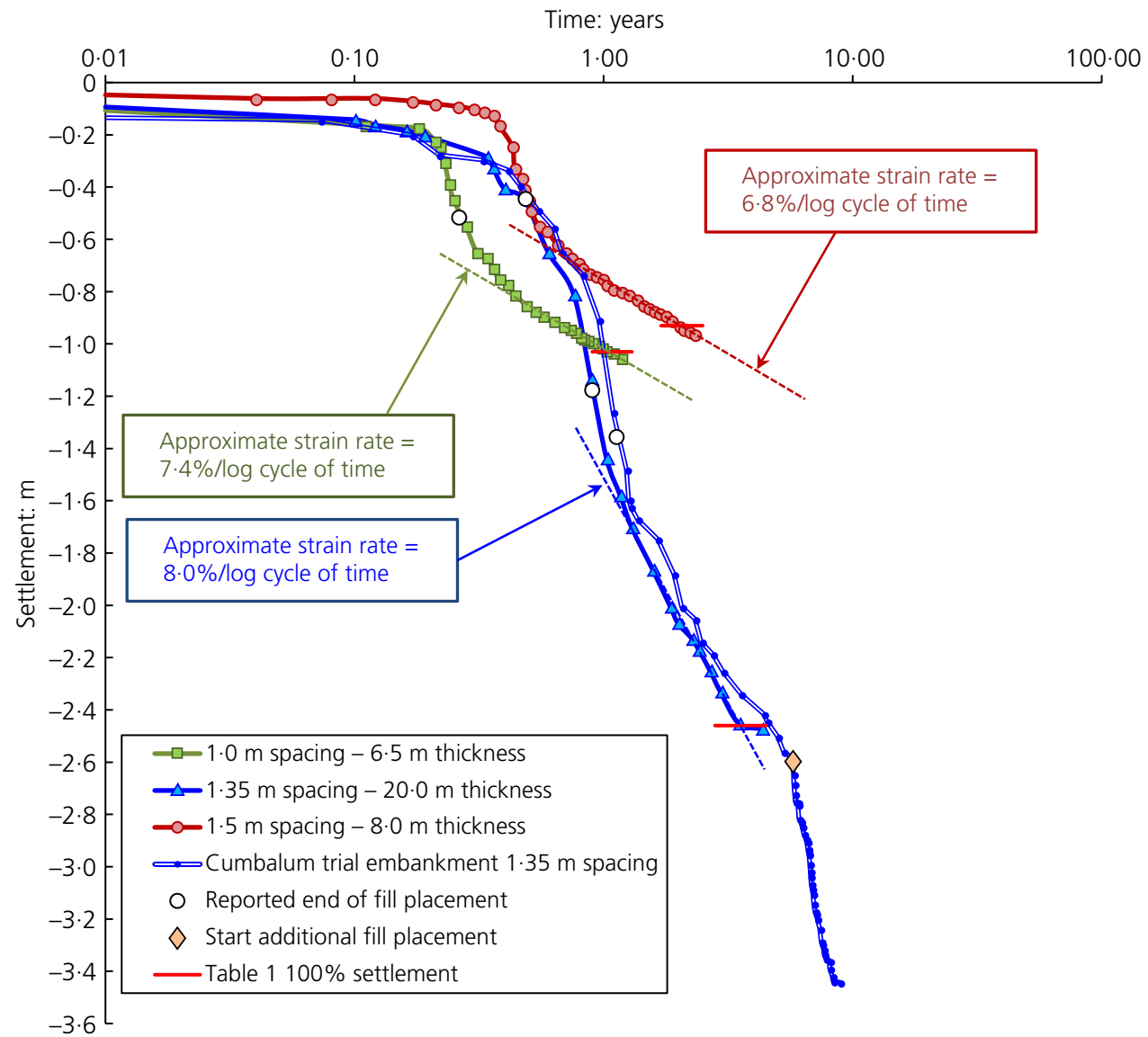

Figure 9. Settlement plotted against log-time - Pimlico Clay 


\section{Offprint provided courtesy of www.icevirtuallibrary.com Author copy for personal use, not for distribution}

changes in the degree of Consolidation. For example, Figure 10 depicts radial Consolidation curves for a range of parameters. At year 3, the difference between $\sim 100$ and $\sim 80 \%$ consolidation (depicted by the arrow) reflects a reduction in $C_{\mathrm{h}}$ with an order of magnitude typical of values for normally consolidated and/or de-structured compressible marine clays postyield. This highlights some of the many challenges involved in back-analysis of wick drain performance and the dilemma facing designers when selecting parameters for prediction when there are so many variables to consider.

Due to the likelihood of Consolidation being incomplete, the findings in the paper were that

- drain spacing (and hence the associated disturbance) did not have a material effect on settlement performance

- the $C_{\mathrm{h}}$ values adopted as applicable, namely around $3 \mathrm{~m}^{2} /$ year at depth increasing to around $6 \mathrm{~m}^{2} /$ year at about $3 \mathrm{~m}$, appear to be derived from the in situ test data obtained prior to embankment loading.

These findings cannot be unequivocally confirmed with the data as presented.

Recognising the inherent difficulties, sensitivity and multivariable possibilities in determining applicable smear parameters, the performance data on Pimlico Clay are a valuable addition to the topic, but it is suggested that the findings of the paper be considered and applied with prudent caution.

\section{Author's reply}

The author thanks the discusser for his interest in the paper and on the topic of consolidation in general.

The intent of the paper was to assess the values of parameters relating to around wick drains based on field observations of settlement. A number of simplifying assumptions were made and the author hopes that these were explained with clarity. Assumptions introduce uncertainty into the assessment, which is why possible values for smear parameters were reported as a range.

The settlement definition for the degree of consolidation was chosen for convenience. Surface settlement can be approximated as the integration of consolidation for the layer in question. Pore pressure, by contrast, is measured at discrete locations in the ground and could not be used for the purposes of this assessment. The use of pore pressure measurements also has its limitations. The sensors are nominally installed at the centre of a wick drain grid, but their actual location is unknown. Pressure sensors installed at the centre of a grid measure the maximum pore pressure and this is not equal to

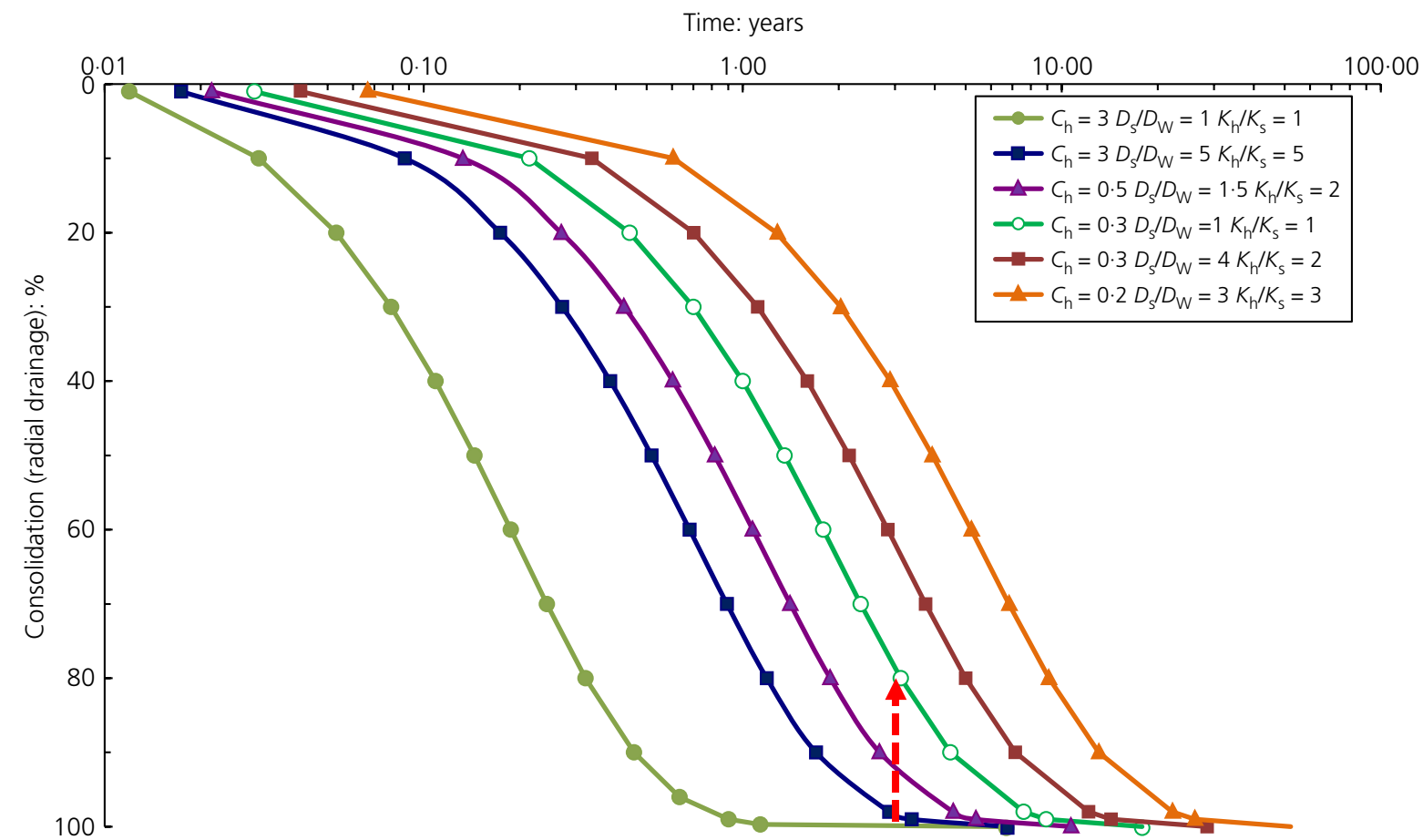

Figure 10. Consolidation (radial drainage) plotted against time -

wicks at $1.35 \mathrm{~m}$ spacing 
the average pressure assumed in conventional consolidation calculations. Pore pressure sensors settle and need to be corrected to account for time-dependent changes in the static water level. The hydrostatic water level changes with time and is rarely measured with the same frequency as piezometers. The soft clays at Ballina were often subject to volume strains in the order of $15-25 \%$ and fell into the large strain category. In large strain theory, pore pressure dissipation lags behind surface settlement.

The discusser is quite correct in stating that there are many inherent difficulties, sensitivities and multivariate possibilities when making such an assessment as performed by the author. The findings of the paper should be viewed as guidance rather than a recommendation and the author agrees that engineers should use their own judgement.
The discusser queried the time for fill construction at one location. The author can confirm that the time for filling quoted in the paper is correct.

\section{REFERENCES}

Allman MA (2004) Cumbalum instrumented embankment Ballina bypass. Proceedings of the 9th Australia New Zealand Conference on Geomechanics, Auckland, New Zealand, pp. 328-334.

Kelly RB (2008) Back analysis of the Cumbalum trial embankment. Australian Geomechanics 43(1): 47-54.

Kelly RB (2014) Assessment of smear parameters for use in wick drain design. Proceedings of the Institution of Civil Engineers - Ground Improvement 167(3): 186-191, http://dx.doi.org/10.1680/grim.13.00007. 